\title{
Differential miRNA expression in Rehmannia glutinosa plants subjected to continuous cropping
}

Yanhui Yang ${ }^{\dagger}$, Xinjian Chen ${ }^{\dagger}$, Junying $\mathrm{Chen}^{\dagger}$, Haixia $\mathrm{Xu}^{\dagger}$, Juan $\mathrm{Li}^{\dagger}$ and Zhongyi Zhang ${ }^{*}$

\begin{abstract}
Background: The productivity of the medicinally significant perennial herb Rehmannia glutinosa is severely affected after the first year of cropping. While there is some information available describing the physiological and environmental causes of this yield decline, there is as yet no data regarding the changes in gene expression which occur when the species is continuously cropped.

Results: Using a massively parallel (Solexa) DNA sequencing platform, it was possible to identify and quantify the abundance of a large number of $R$. glutinosa miRNAs. We contrasted the miRNA content of first year crop plants with that of second year crop ones, and were able to show that of 89 conserved (belonging to 25 families) and six novel miRNAs (six families), 29 of the former and three of the latter were differentially expressed. The three novel miRNAs were predicted to target seven genes, and the 29 conserved ones 308 genes. The potential targets of 32 of these differentially expressed miRNAs involved in the main transcription regulation, plant development and signal transduction. A functional analysis of the differentially expressed miRNAs suggested that several of the proposed targets could be directly or indirectly responsible for the development of the tuberous root.

Conclusion: We have compared differential miRNAs expression in the first year crop (FP) R. glutinosa plants and second year crop (SP) ones. The outcome identifies some potential leads for understanding the molecular basis of the processes underlying the difficulty of maintaining the productivity of continuously cropped $R$. glutinosa.
\end{abstract}

\section{Background}

Rehmannia glutinosa L. is a perennial herbaceous species belonging to the Scrophulariaceae family. Its economic importance results from the medicinal activity present in extracts of its tuberous roots [1]. Because of a lack of known undesirable side effects and its relatively low price, the species is extensively used in traditional Chinese clinical practice. Its prime production region is the Huai area of central China, but the climatic and edaphic conditions in Jiaozuo (Henan province) are also conducive for the cultivation of a high quality product. After one season of production, however, disease buildup (and other factors) forces the land to be cultivated with other crops for a period of 15-20 years [2]. Even in the absence of disease pressure, attempts to continuously

\footnotetext{
* Correspondence: hauzzy@163.com

† Contributed equally

College of Agronomy, Henan Agricultural University, 95 Wenhua Road,

Zhengzhou, PR China
}

crop over several seasons have failed to overcome the major decline in productivity, as the tubers are increasingly replaced by fibrous roots, which are unable to develop into tubers $[3,4]$. Much of the past research aimed at identifying the causative factors for this continuous cropping yield decline has been focused on the physiological activity and autotoxicity of the root exudates [5-7]. However, the molecular basis of the species' sensitivity to its own exudate remains unknown.

miRNAs (short RNA molecules, on average $\sim 21$ nucleotides in length) underlie a number of biological phenomena in the animal, plant and virus kingdoms [8], largely at the level of post-transcriptional gene regulation [9-12]. As their sequences are so highly conserved across the eukaryotes, they are believed to represent an evolutionarily ancient component of gene regulation. They operate via their complementarity to a stretch of mRNA sequence, and affect the level of gene expression by targeting the mRNA molecule for degradation. 
The short stretch of sequence present in an miRNA means that many probably interact with a number of independent mRNAs. Commonly, the miRNA target sequence lies within a coding region, although there are examples of sites lying in either the 3' or 5' untranslated region [13-15]. The spectrum of functions now known to be miRNA-regulated is very diverse [16-20] and includes many aspects of plant growth and development [21-32].

Our hypothesis here was that miRNA activity may underlie some at least of the the problems associated with the continuous cropping of $R$. glutinosa. In order to gain a global picture of the miRNA content of $R$. glutinosa, we have therefore employed a high throughput parallel sequencing platform (Solexa sequencing) able to generate millions of short (18-30 nt) reads with a high level of accuracy. We have applied this technology to enable the comparative profiling of the miRNA content of plants in their first year of cropping (FP) with those in their second year (SP), with the intention of identifying miRNAs expressed differentially in FP and SP plants.

\section{Results and Discussion}

\section{Sequencing and annotation of $R$. glutinosa miRNAs}

Solexa sequencing of the FP and SP miRNA libraries yielded, respectively, 17,619,697 and 18,028,647 unfiltered sequence reads. Of these $19.92 \%$ (unique 39.37\%) were FP-specific, 23.82\% (unique 48.17\%) were SP-specific and $56.26 \%$ (unique $12.46 \%$ ) were their common respectively. The average number of occurrences of the sequences common to both libraries was 10.5 , while that of library-specific reads was not more than 1.2 (Table 1). After discarding the low quality reads, a total of 14,630,881 FP and 15,644,334 SP reads was retained. These sequences represented 6,748,998 and 7,894,661 unique clean reads in FP and SP, respectively. Their size distribution (Figure 1) showed that $\sim 94 \%$ of the sequences in both libraries were of length 20-24 nt, with the modal length of $24 \mathrm{nt}$ and the third peak at $21 \mathrm{nt}$, consistent with the observed length distribution of mature plant miRNAs $[33,34]$.

\section{Conserved miRNAs}

Sequences homologous to non-coding sequences (rRNA, tRNA, small nuclear RNA and small nucleolar RNA) were identified from a search of the GenBank and the
Rfam9.1 databases. This resulted in the allocation of $0.93 \%$ of the FP and $0.63 \%$ of the SP unique miRNAs to this category. When the remaining sequences were queried against known miRNA sequences, the outcome was the identification of 282,063 (unique 300) and 118,011 (unique 251) hits, accounting for, respectively, 1.93\% and $0.75 \%$ of the FP and SP libraries. A BLASTn search of the genic miRNAs resulted in the identification of 89 sequences, belonging to 25 families. The extent of their conservation across the plant kingdom was shown by an alignment with the whole genome sequences of A. thaliana, soybean, rice, black poplar and grape (Table S1 in Additonal file 1). The most abundant sequences were miR156/157, miR172 and miR165/166; the former accounted for $\sim 47 \%$ of all conserved miRNAs in the FP library, while the most frequent single conserved sequence in the SP library was miR172 ( 39\%) (Figure 2). In both libraries, miR159, miR394 and miR403 were moderately abundant. The five miRNAs miR161, miR397, miR398, miR408 and miR822 were absent from the SP library. It appeared therefore that the miRNA population present in FP plants differed to some extent from that present in SP plants.

\section{Novel miRNAs}

A distinguishing feature of miRNAs is the ability of their pre-miRNA sequences to adopt the canonical stem-loop hairpin structure. After removal of the conserved miRNAs, 13,724,517 FP $(6,685,869$ unique sequences) and $15,043,261$ (7,845,823 unique sequences) SP sequences were aligned with the $A$. thaliana genome sequence, producing 7,341 (3,158 unique sequences) $\mathrm{FP}$ and 7,468 (3,269 unique sequences) SP sequences (Table 2) whose flanking region (in A. thaliana, at least) was amenable to secondary structure analysis. The application of a set of strict identification criteria for potential miRNA loci $[35,36]$ resulted in the selection of 18 sequences (Additional file 2) across the two libraries which could be considered as likely novel miRNAs (Table S2 in Additional file 1). Except for miR5138, their frequency of occurrence was $<40$ (Table S2 in Additional file 1), reflecting an expression level considerably lower than that of the majority of the conserved miRNAs. When RT-PCR was applied to these 18 sequences, six were amplifiable from $R$. glutinosa cDNA template (Figure 3).

Table 1 Small RNA sequences present in both FP and SP plants, and those specific to one or other plant type

\begin{tabular}{cccccc}
\hline Class & $\begin{array}{c}\text { Unique } \\
\text { sequences }\end{array}$ & $\begin{array}{c}\text { Percentage } \\
\text { Percentage (\%) }\end{array}$ & $\begin{array}{c}\text { Total } \\
\text { sequences }\end{array}$ & Percentage (\%) & $\begin{array}{c}\text { Mean } \\
\text { frequency }\end{array}$ \\
\hline Total reads & $130,20,836$ & $100.00 \%$ & 30275211 & $100.00 \%$ & 2.33 \\
FP and SP Common & $1,622,823$ & $12.46 \%$ & $17,033,751$ & $56.26 \%$ & 10.50 \\
FP specific & $6,271,838$ & $48.17 \%$ & $7,211,298$ & $23.82 \%$ & 1.15 \\
SP specific & $5,126,175$ & $39.37 \%$ & $6,030,162$ & $19.92 \%$ & 1.18 \\
\hline
\end{tabular}




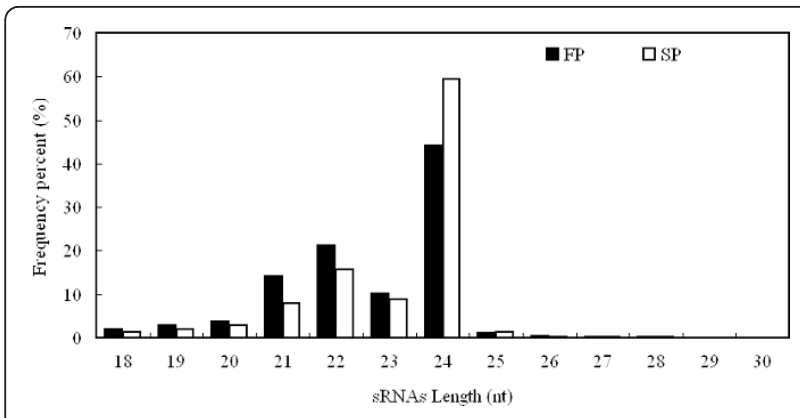

Figure 1 Size distribution of $R$. glutinosa small RNAs.

\section{Differentially expressed miRNAs}

Evidence for differential expression in FP and SP plants was sought by comparing the frequency of occurrence of the 89 conserved and six novel miRNAs, based on a
Poisson distribution approach [37]. The 29 conserved (11 miRNA families) and three novel miRNAs showing the greatest degree of differential expression are listed in Table 3. Of these 32 sequences, 12 showed a greater than two fold difference in expression level between FP and SP plants. Seven of them were more strongly expressed in SP than in FP plants. The expression levels of the most differentially expressed (17 conserved and 3 novel) miRNAs were reanalysed using qRT-PCR. This confirmed that 14 of the former and two of the latter sequences were indeed differentially expressed in FP and SP plants (Figure 4), showing that frequency of occurrence in Solexa runs produces a reasonably accurate prediction for expression level. Expression levels of 4 miRNAs (miR157a, miR167a, miR160a and miR5138) in roots were measured in different times (Figure 5). miR157a and miR167a were highly expressed in FP,
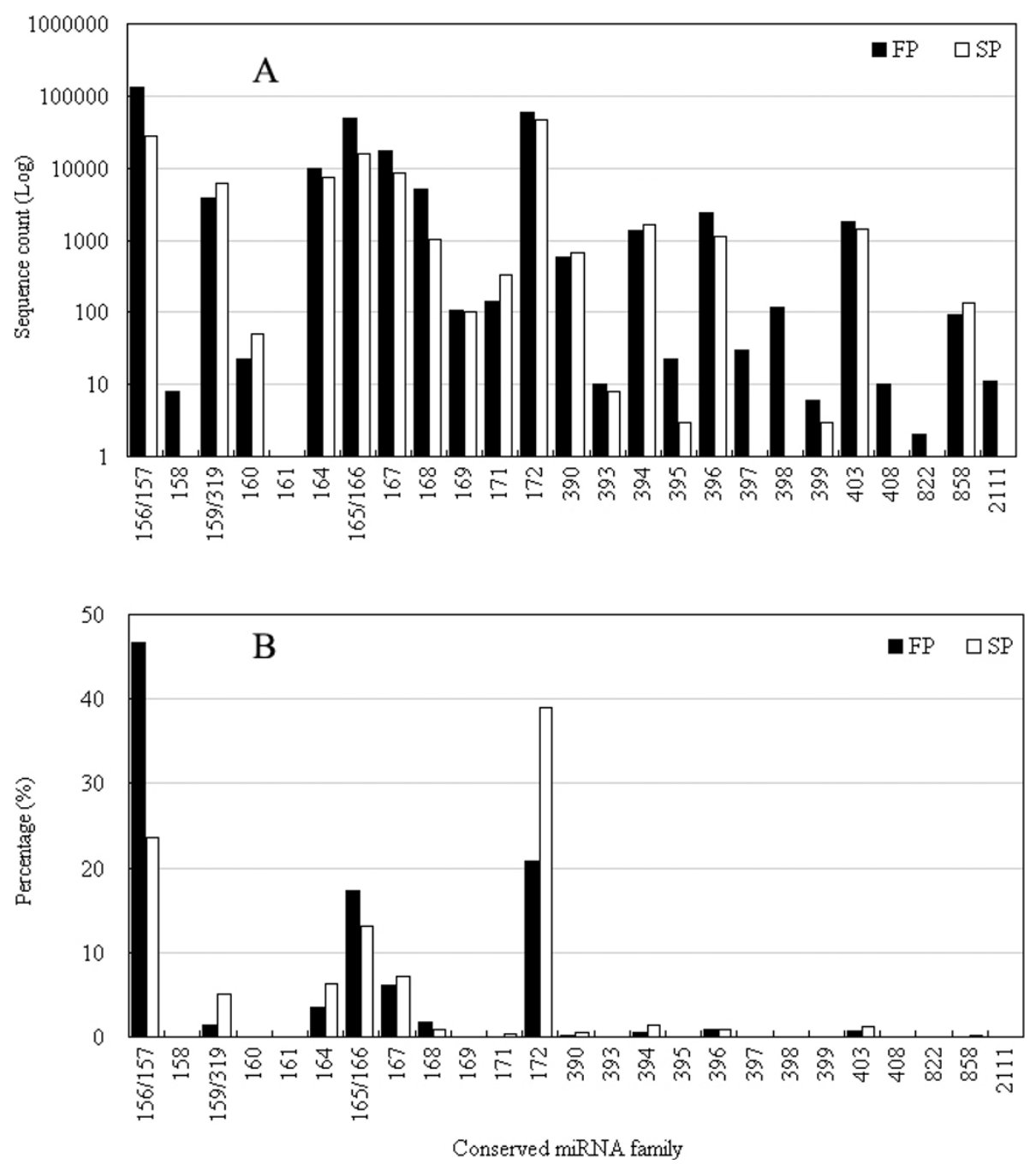

Figure 2 The relative abundance of conserved miRNA sequences. (A) The number of occurrences of a sequence. (B) The ratio between the number of sequences in FP (or SP) and the total number in the pooled library. 
Table 2 Annotation of sRNAs sequences from SP and FP

\begin{tabular}{|c|c|c|c|c|c|c|}
\hline \multirow[t]{2}{*}{ Category } & \multicolumn{2}{|c|}{$\begin{array}{c}\text { Unique } \\
\text { signatures }\end{array}$} & \multicolumn{2}{|c|}{$\begin{array}{c}\text { Total } \\
\text { signatures }\end{array}$} & \multicolumn{2}{|c|}{$\begin{array}{c}\text { Mean } \\
\text { frequency }\end{array}$} \\
\hline & FP & SP & FP & SP & FP & SP \\
\hline Non-protein-coding RNAs & $62,829(0.93 \%)$ & $48,587(0.63 \%)$ & $624,301(4.26 \%)$ & $483062(3.08 \%)$ & 9.94 & 9.94 \\
\hline rRNA & $52,498(0.78 \%)$ & $39,983(0.51 \%)$ & $472,541(3.23 \%)$ & $346,969(2.22 \%)$ & 9 & 8.68 \\
\hline snRNA & $1,461(0.02 \%)$ & $1,304(0.02 \%)$ & $2,607(0.02 \%)$ & $2,158(0.01 \%)$ & 1.78 & 1.66 \\
\hline SnORNA & $542(0.01 \%)$ & $513(0.01 \%)$ & $731(0.00 \%)$ & $709(0.00 \%)$ & 1.35 & 1.38 \\
\hline tRNA & $8,328(0.12 \%)$ & $6,787(0.09 \%)$ & $148,422(1.01 \%)$ & $133,226(0.85 \%)$ & 17.82 & 19.63 \\
\hline Known miRNAs & $300(0.00 \%)$ & $251(0.00 \%)$ & $282,063(1.93 \%)$ & $118,011(0.75 \%)$ & 940.21 & 470.16 \\
\hline Matched to $A$. thaliana genome & $3,158(0.05 \%)$ & $3,269(0.04 \%)$ & $7,341(0.05 \%)$ & $7,468(0.04 \%)$ & 2.32 & 2.28 \\
\hline Other sRNAs & $6,682,711(90.01 \%)$ & $7,842,554(99.36 \%)$ & $13,717,176(93.76 \%)$ & $15,035,793(96.12 \%)$ & 2.05 & 1.92 \\
\hline Total & $6,748,998(100 \%)$ & $7,894,661(100 \%)$ & $14,630,881(100 \%)$ & $15,644,334(100 \%)$ & 2.17 & 1.98 \\
\hline
\end{tabular}

while miR160a and miR5138 were quite opposite, with strongly expressing in SP.

\section{Target prediction for the three differentially expressed novel miRNAs}

The target of most plant miRNAs possesses a single perfect or near perfect complementary site in the coding region $[13,15]$. Assuming this to be generally the case, the A. thaliana gene space was searched for complementarity with the sequences of the three differentially expressed novel miRNAs. Using a set of rules for predicting novel miRNA potential target genes $[14,38]$, this exercise predicted seven potential targets, with miR5138 and miR5140 both targeting more than one gene (Table S3 in Additional file 1). The targets encoded the following gene products: ICU2 (INCURVATA2), a DNA-directed DNA polymerase, a magnesium transporter CorA-like family protein, an ATP synthase ( $\alpha$ chain), a TIR-NBS-LRR protein, a ZIGA4 (ARF GAP-like zinc finger-containing protein ZiGA4) and a DC1 domain-containing protein.

\section{Function of the potential targets of differentially expressed miRNAs}

An indication of the genes responsible for the continuous cropping syndrome was sought by an inspection of the 308 potential targets of the 29 differentially

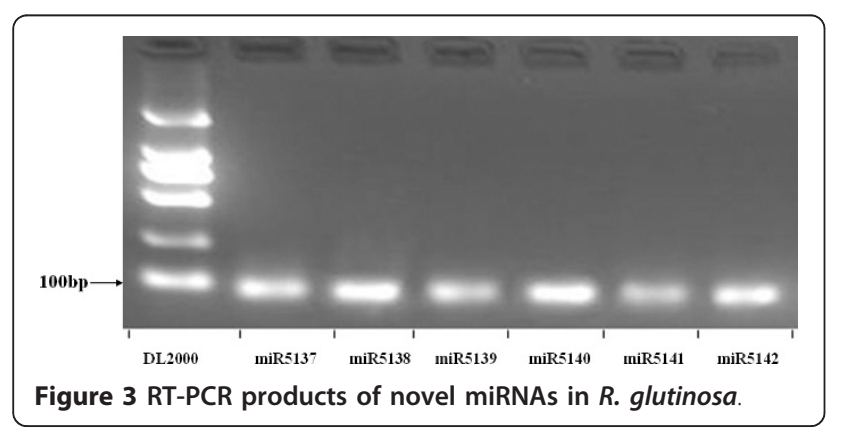

expressed miRNAs (Additional file 3) in addition to the seven targets of the novel miRNAs (Table S3 in Additional file 1). Gene ontology categories were assigned to all 315 putative targets according to their cellular component, their molecular function and the biological process(es) they are involved in A. thaliana (Figure 6). With respect to molecular function, the targets fell largely into nine categories, with the three most overrepresented being nucleic acid binding, metal ion binding and transcription factor activity. Twelve biological processes were identified, with the three most frequent being the regulation of transcription, plant development and signal transduction. The potential targets for the 32 differentially expressed miRNAs mainly involved transcription, plant development and signal transduction.

Several of these targets may be directly or indirectly involved in the development of tuberous vs fibrous roots (Figure 7, 8). For example, miR156/157 targets an SPL transcription factor, which when over-expressed in A. thaliana, produces an early flowering phenotype. The over-expression of miR156/157 itself delays flowering [39-41]. Thus it is possible that in $R$. glutinosa, a higher level of expression of miR156/157 (as occurred in FP plants) could prolong root growth and development. The miR160 target is the auxin response factor ARF17, while those of miR167 are ARF6 and ARF8. ARF17 is a negative regulator, while ARF6 and ARF8 are positive regulators of adventitious rooting. These three ARFs share overlapping expression domains, interact genetically and regulate one another's expression at both the transcriptional and post-transcriptional level [42]. Since SP plants express more miR160 and less miR167 than FP plants, it is possible that the balance of ARF protein present is altered by continuous cropping, and hence there is an effect on tuberous root expansion. The target of miR5138 is the gene ICU2, which is negative regulator of floral homeotic genes in A. thaliana. Its overexpression delays flowering, while its knock-out hastens 
Table 3 miRNAs expressed differentially in FP and SP plants

\begin{tabular}{|c|c|c|c|c|c|c|c|}
\hline \multirow[t]{2}{*}{ miRNAs } & \multicolumn{2}{|c|}{$\begin{array}{l}\text { Sequencing } \\
\text { frequency }\end{array}$} & \multicolumn{2}{|c|}{$\begin{array}{l}\text { Normalized } \\
\text { value }\end{array}$} & \multirow[t]{2}{*}{$\begin{array}{l}\text { Fold-change } \\
\left(\log _{2} \text { SP/FP }\right.\end{array}$} & \multirow[t]{2}{*}{ P-value } & \multirow[t]{2}{*}{ Significance } \\
\hline & $\mathrm{FP}$ & SP & FP & SP & & & \\
\hline rgl-miR156a & 2,945 & 1,526 & 201.29 & 97.54 & -1.05 & 0.00 & $* *$ \\
\hline rgl-miR156b & 63 & 30 & 4.31 & 1.92 & -1.17 & 0.00 & $* *$ \\
\hline rgl-miR156f & 40 & 14 & 2.73 & 0.89 & -1.61 & 0.00 & $* *$ \\
\hline rgl-miR157a & 126,264 & 24,968 & $8,613.21$ & $1,595.98$ & -2.43 & $3.45 E-263$ & $* *$ \\
\hline rgl-miR157b & 2,154 & 1,071 & 147.22 & 68.46 & -1.1 & 4.40E-05 & $* *$ \\
\hline rgl-miR157c & 221 & 87 & 15.11 & 5.56 & -1.44 & $1.26 \mathrm{E}-11$ & $* *$ \\
\hline rgl-miR157d & 158 & 53 & 10.8 & 3.39 & -1.67 & 0.00 & $* *$ \\
\hline rgl-miR160a & 17 & 47 & 1.16 & 3 & 1.37 & $7.87 \mathrm{E}-16$ & $* *$ \\
\hline rgl-miR160b & 2 & 26 & 0.14 & 1.66 & 3.6 & 0.00 & $* *$ \\
\hline rgl-miR160c & 3 & 32 & 0.21 & 2.05 & 3.32 & 0.00 & $* *$ \\
\hline rgl-miR164b & 153 & 62 & 9.71 & 3.96 & -1.29 & 0.00 & $* *$ \\
\hline rgl-miR166a & 15,257 & 4,835 & 968.6 & 309.06 & -1.65 & 0.00 & $* *$ \\
\hline rgl-miR166b & 15,607 & 4,964 & 990.82 & 317.3 & -1.64 & $3.65 \mathrm{E}-66$ & $* *$ \\
\hline rgl-miR166c & 17,639 & 5,735 & $1,119.82$ & 366.59 & -1.61 & 0.00 & $* *$ \\
\hline rgl-miR167a & 8,673 & 4,231 & 550.61 & 270.45 & -1.03 & 0.00 & $* *$ \\
\hline rgl-miR167b & 8,164 & 3,965 & 518.29 & 253.45 & -1.03 & 0.00 & $* *$ \\
\hline rgl-miR167d & 689 & 317 & 43.74 & 20.26 & -1.11 & 0.00 & $* *$ \\
\hline rgl-miR168a & 2,520 & 494 & 159.98 & 31.58 & -2.34 & 0.00 & $* *$ \\
\hline rgl-miR168b & 2,547 & 512 & 161.70 & 32.73 & -2.3 & 0.00 & $* *$ \\
\hline rgl-miR171a & 101 & 234 & 6.41 & 14.96 & 1.22 & $2.82 E-59$ & $* *$ \\
\hline rgl-miR171b & 37 & 81 & 2.35 & 5.18 & 1.14 & 0.00 & $* *$ \\
\hline rgl-miR395a & 26 & 3 & 1.65 & 0.19 & -3.11 & 0.00 & $* *$ \\
\hline rgl-miR395b & 11 & 0 & 0.7 & 0.06 & -3.45 & 0.00 & $* *$ \\
\hline rgl-miR396a & 1,331 & 577 & 84.5 & 36.88 & -1.2 & 0.00 & $* *$ \\
\hline rgl-miR396b & 656 & 295 & 41.65 & 18.86 & -1.14 & 0.00 & $* *$ \\
\hline rgl-miR396c & 451 & 221 & 28.63 & 14.13 & -1.02 & 0.00 & $* *$ \\
\hline rgl-miR397a & 30 & 0 & 1.9 & 0.01 & -7.57 & 0.00 & $* *$ \\
\hline rgl-miR398a & 76 & 0 & 4.82 & 0.01 & -8.91 & $8.50 \mathrm{E}-36$ & $* *$ \\
\hline rgl-miR398b & 37 & 0 & 2.35 & 0.01 & -7.88 & $3.24 \mathrm{E}-10$ & $* *$ \\
\hline rgl-miR5138 & 32 & 84 & 2.81 & 7.67 & 1.44 & 0.00 & $* *$ \\
\hline rgl-miR5140 & 39 & 5 & 1.51 & 0.20 & -2.96 & 0.00 & $* *$ \\
\hline rgl-miR5142 & 0 & 30 & 0.01 & 2.94 & 8.2 & 0.00 & $* *$ \\
\hline
\end{tabular}

it [43]. Since this miRNA is more highly expressed in SP than in FP plants, there may be a differential expression of ICU2 and hence an effect on flowering time, with a knock-on effect on tuberous root expansion.

These predicted target genes were cloned in $R$. glutinosa (Table 4 and Additional file 4) and registered as ESTs in NCBI.

Overall, there was a suggestion that the expression of a number of miRNA families may be correlated with the continuous cropping syndrome in $R$. glutinosa. Whether these miRNAs actually regulate key genes responsible for the syndrome will require experimental demonstration. The identification of these miRNAs has nevertheless succeeded in providing leads for determining the molecular genetic basis of the continuous cropping syndrome in $R$. glutinosa.

\section{Conclusions}

Here we have described the application of a combination of approaches to identify a set of 89 conserved (belonging to 25 families) and six novel $R$. glutinosa miRNAs, which are differentially, expressed in first and second year crops. We believe that this information could provide initial candidates for the genes responsible for tuberous root expansion, and in particular for the syndrome of continuous cropping yield decline in this medicinally important species.

\section{Methods}

Plant material and RNA isolation

R. glutinosa cultivar "Wen 85-5" was collected from the Wen Agricultural Institute, Jiaozuo City, Henan Province, China. The first year crop (FP) was grown from 


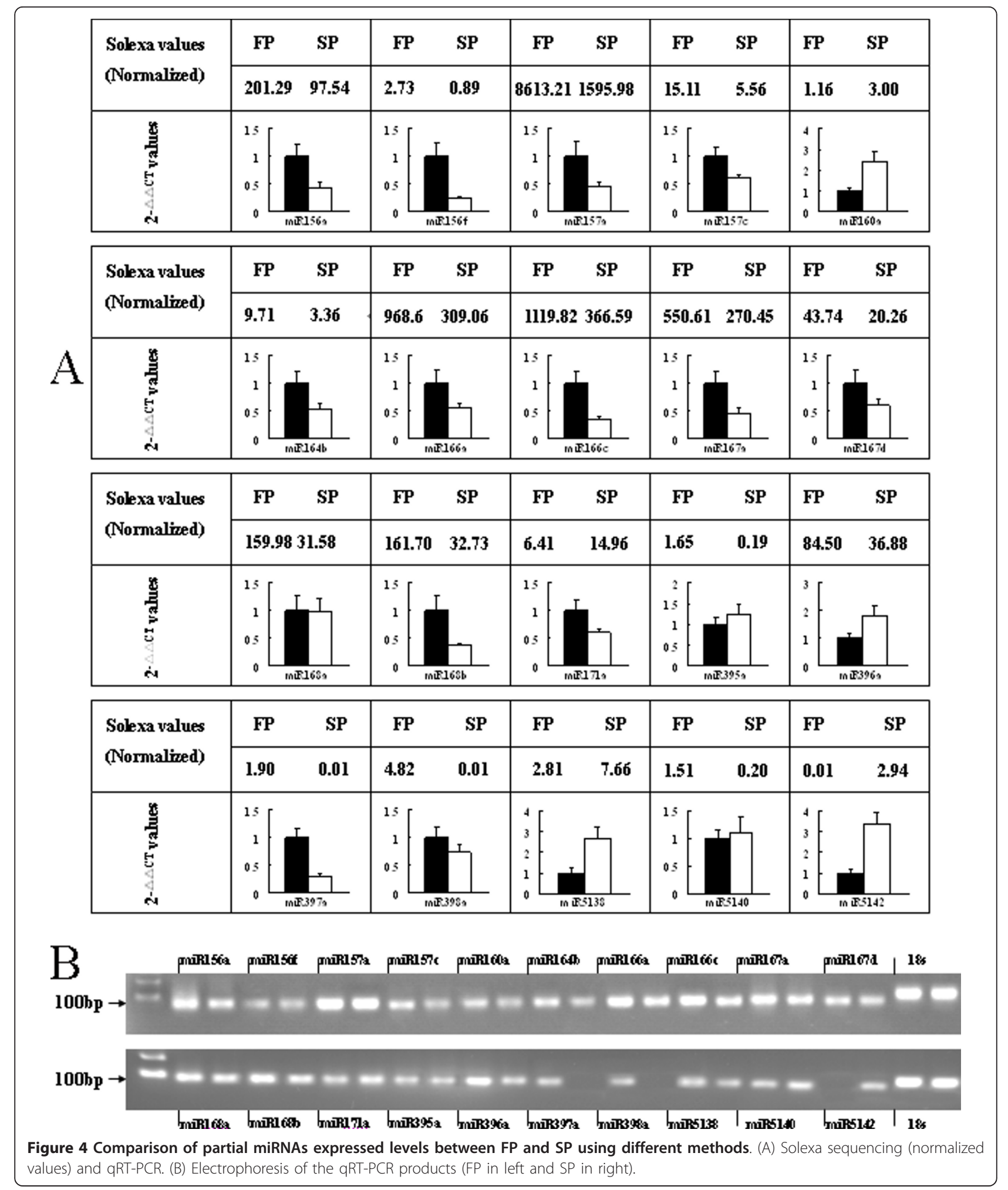




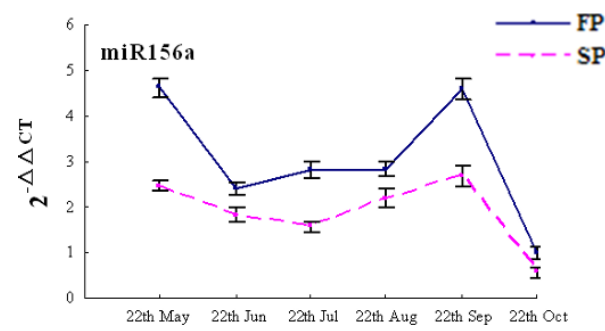

Dates of collecting samples

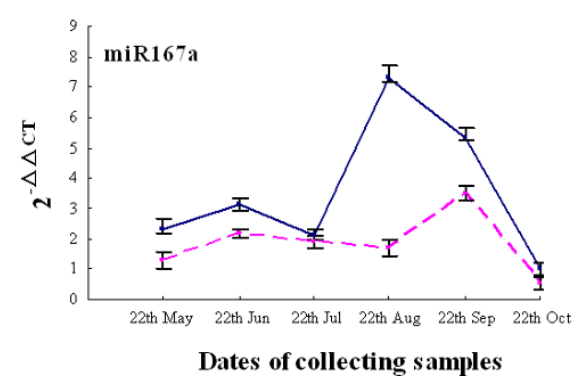

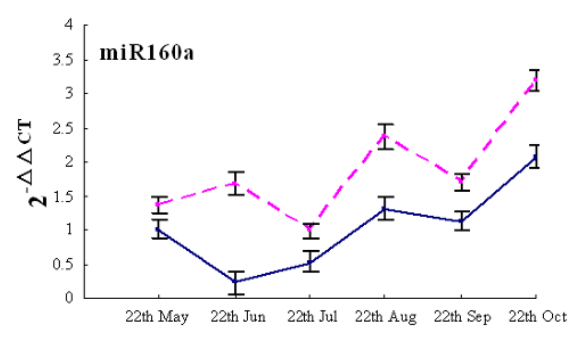

Dates of collecting samples

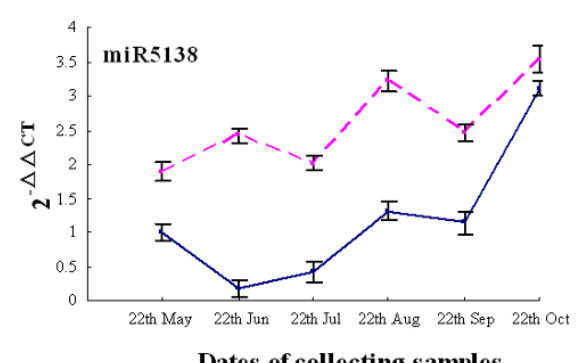

Dates of collecting samples

Figure 5 Differential expression levels of 4 miRNAs in roots

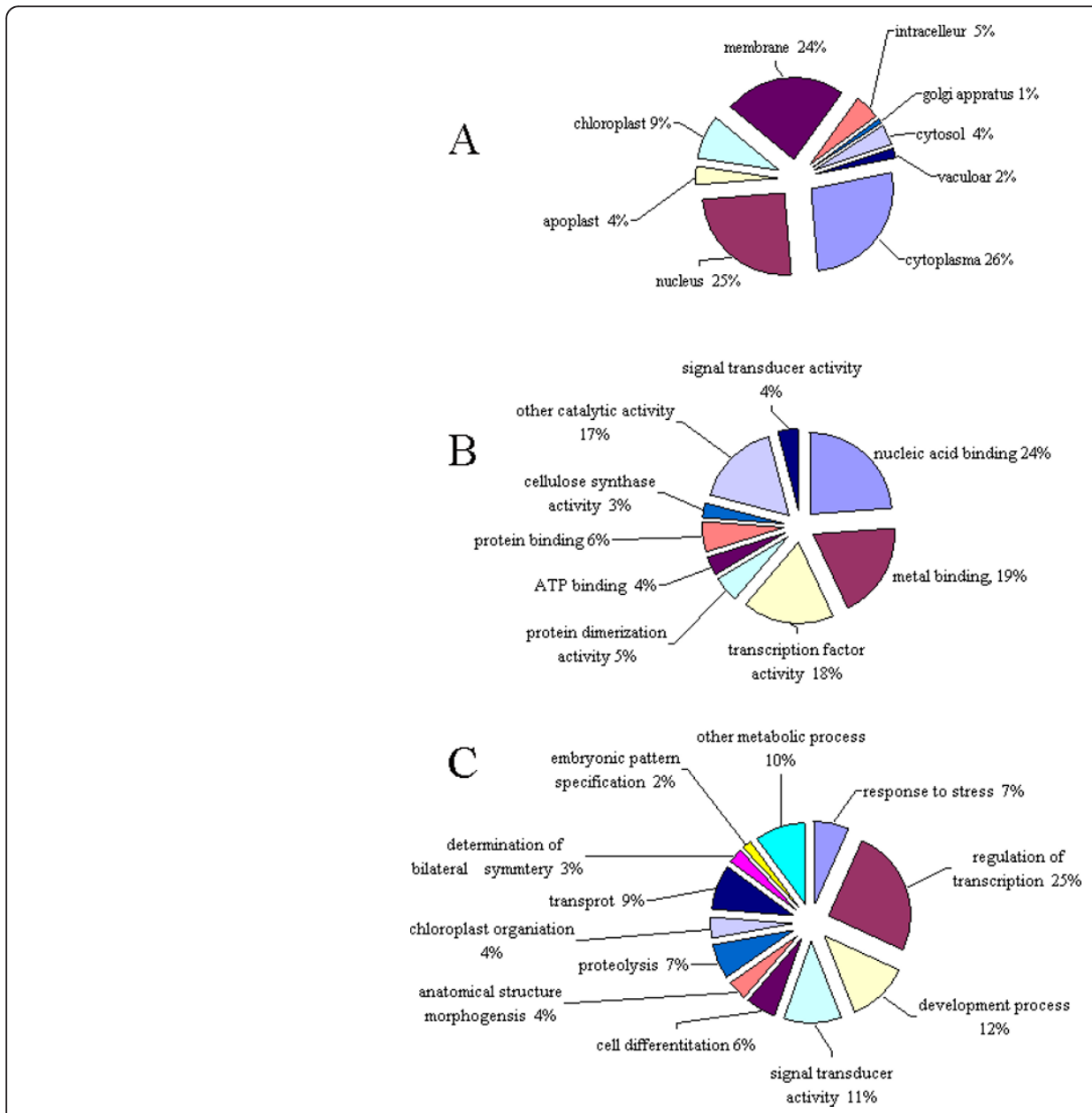

Figure 6 Gene ontology of the predicted targets for 32 differentially expressed miRNAs. Categorization of miRNA-target genes was performed according to the cellular component (A), molecular function (B) and biological process (C). 


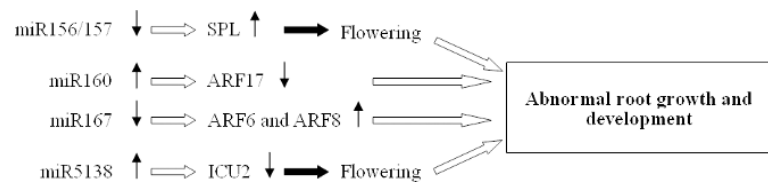

Figure 7 Possible functions between differentially expressed miRNAs and their targets in growth and development of $R$. glutinosa. $\uparrow$ : up- regulation of expression, $\downarrow$ : down-regulation of expression. Empty arrows imply inhibition of phenotype, while solid arrows indicate its promotion.

April 15 to November 30 2009, and the second year crop (SP) was planted on the same date, but on land where a first crop had been grown the previous year (plant growth period was between April 15, 2008 and November 30, 2008) (Figure 8). Leaf, stem and root samples were taken from five independent plants at the tuberous root expansion stage (August 15, 2009), and their RNA content was extracted with the TriZOL reagent (TaKaRa Co., Tokyo, Japan). Total RNA from each plant was pooled, and then separated by $15 \%$ denaturing PAGE to recover the population of small RNAs (size range 18-30 nt) present.
For the measure of differently expressed miRNAs in various development stages of $R$. glutinosa, FP and SP plants (cultivar "Wen 85-5") were grown in the isolated plots from April 22 to October 22, 2010. Roots of $R$. glutinosa were collected every month and total RNAs were extracted with TriZOL reagent.

\section{miRNA library construction and sequencing}

The small RNAs were ligated sequentially to 5' and 3' RNA/DNA chimeric oligonucleotide adaptors (Illumina), and the resulting ligation products were gel purified by $10 \%$ denaturing PAGE, and reverse transcribed. The cDNAs obtained in this way were sequenced on a Genome Analyzer IIx System by Beijing Genomics Institute (BGI) (Shenzhen, China).

\section{Identification of miRNAs}

Conserved miRNAs were identified by blastn searches against Genbank http://www.ncbi.nlm.nih.gov, Rfam 9.1 (rfam.janelia.org) and miRBase $15.0 \mathrm{http} / / /$ www.mirbase. org databases with default parameters. Potentially novel sequences were identified by an alignment with the A. thaliana genome sequence $\mathrm{ftp} / / \mathrm{ftp}$.tigr.org/pub/data/

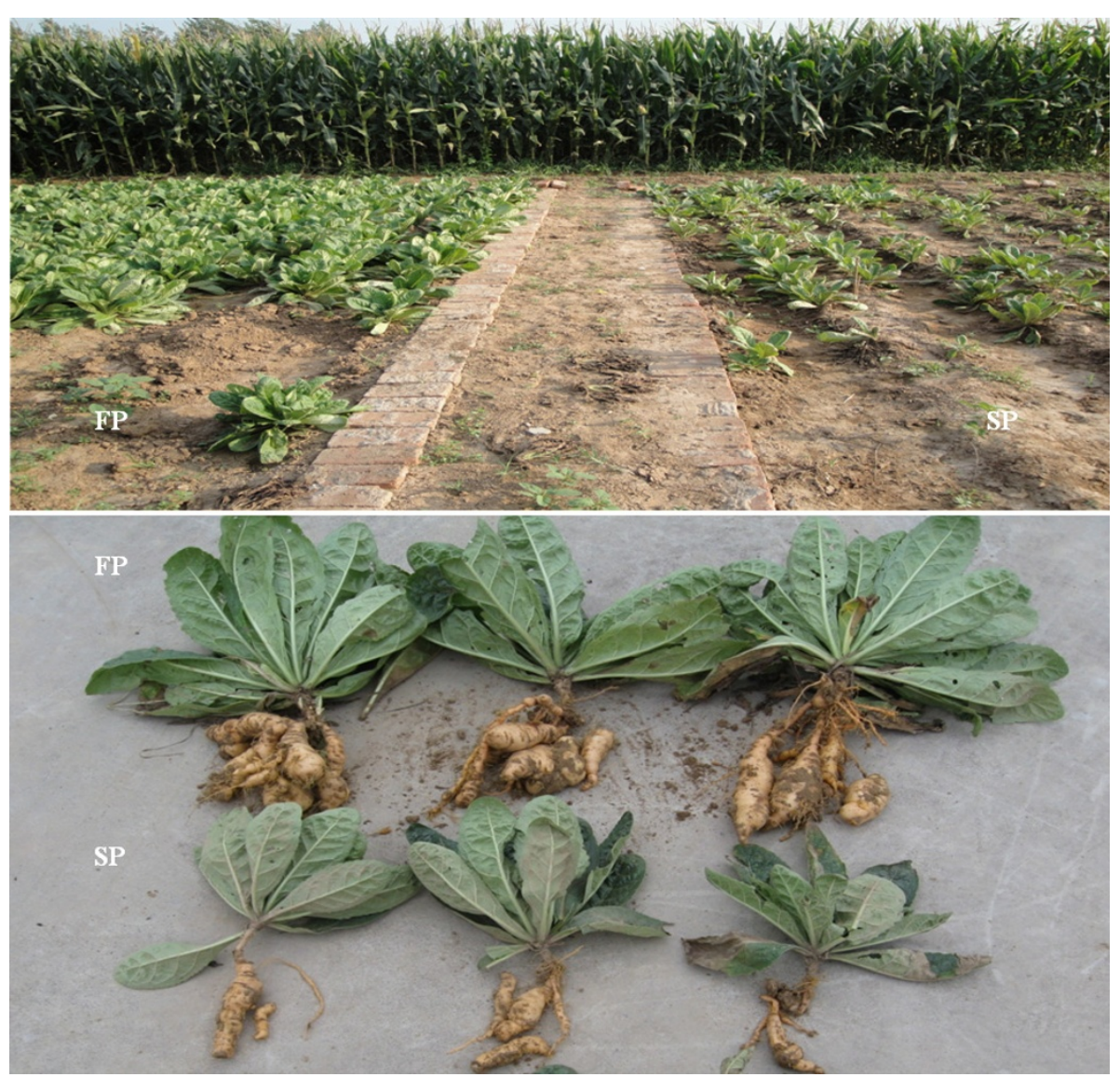

Figure 8 Difference of FP and SP R. glutinosa plants. 
Table 4 Partial targets cloned in R. glutinosa

\begin{tabular}{ccccc}
\hline miRNAs & $\begin{array}{c}\text { Target Acc. } \\
\text { of } \text { A.thaliana }\end{array}$ & $\begin{array}{c}\text { Genbank Acc. of targets } \\
\text { cloned in }\end{array}$ & Identity & $\begin{array}{c}\text { Annotation } \\
\text { (A. thaliana) }\end{array}$ \\
\hline rgl-miR160 & AT4G30080.1 & JG014346 & $79.94 \%$ & ARF16 (Auxin response factor 16) \\
rgl-miR167 & AT1G30330.1 & JG390498 & $67.51 \%$ & ARF6 (Auxin response factor 6) \\
rgl-miR5138 & AT5G67100.1 & JG390599 & $76.68 \%$ & ICU2 (INCURVATA2); DNA-directed DNA polymerase \\
rgl-miR5140 & AT3G58970.1 & JG390538 & $68.87 \%$ & magnesium transporter CorA-like family protein \\
\hline
\end{tabular}

a_thaliana/ath1/SEQUENCES/ using SOAP (soap.genomics.org.cn) software [44]. Candidate pre-miRNAs were identified by folding the flanking genome sequence of distinct miRNAs using MIREAP (mireap.sourceforge. net), followed by a prediction of secondary structure by mFold v3.1 [45]. The criteria chosen for stem-loop hairpins were as suggested elsewhere $[35,36]$.

\section{Reverse transcription (RT) reaction}

For RT, polyA was first added to the 3' end of the miRNAs using polyA polymerase, and cDNA was then synthesized using AMV reverse transcriptase (GeneCopoeia, Inc.), employing a $53 \mathrm{nt}$ oligodT-adaptor sequence (GeneCopoeia, Inc.) as the primer. The former was a $25 \mu \mathrm{l}$ reaction, containing $2 \mu \mathrm{g}$ total RNA, $2.5 \mathrm{U}$ polyA polymerase (GeneCopoeia, Inc.), $1 \mu \mathrm{l}$ RTase mixture (GeneCopoeia, Inc.), and $5 \mu \mathrm{l} 5 \times$ reaction buffer. The reaction was incubated at $37^{\circ} \mathrm{C}$ for $60 \mathrm{~min}$ and $85^{\circ}$ $\mathrm{C}$ for $5 \mathrm{~min}$, and then stored at $-20^{\circ} \mathrm{C}$.

\section{Identification of novel miRNAs using RT-PCR}

Forward primers (sequence given in Table S4 in Additional file 1) were synthesized by Sangon (Shanghai, China). Each $50 \mu \mathrm{l}$ reaction comprised $0.5 \mu \mathrm{l}$ cDNA, $2 \mu \mathrm{l}$ $(2 \mu \mathrm{M})$ miRNA forward primer, $2 \mu \mathrm{l}(2 \mu \mathrm{M})$ reverse primer (Universal Adaptor PCR Primer, GeneCopoeia, Inc.), $5 \mu \mathrm{l} 10 \times$ PCR buffer, $2 \mu \mathrm{l} 10 \mathrm{mM}$ dNTP, $1 \mathrm{U}$ Taq DNA polymerase (Invitrogen, Inc.). The reactions were initially denatured at $95^{\circ} \mathrm{C}$ for $10 \mathrm{~min}$, and then cycled 36 times through $95^{\circ} \mathrm{C} / 10 \mathrm{~s}, 55^{\circ} \mathrm{C} / 20 \mathrm{~s}, 72^{\circ} \mathrm{C} / 10 \mathrm{~s}$. A $5 \mu$ l aliquot of each reaction was subjected to $3 \%$ agarose electrophoresis.

\section{Validation of differential miRNA expression based on qRT-PCR}

qRT-PCR was performed using an All-in-One ${ }^{\mathrm{TM}}$ miRNA Q-PCR detection kit (GeneCopoeia, Inc.) on a BIO-RAD iQ5 real-time PCR detection system (Bio-Rad laboratories, Inc.). Each $20 \mu \mathrm{l} \mathrm{Q}-\mathrm{PCR}$ comprised $0.5 \mu \mathrm{l} \mathrm{cDNA}$, $2 \mu \mathrm{l} 2 \mu \mathrm{M}$ miRNA forward primer (sequence given in Table S5 in Additional file 1), $2 \mu \mathrm{l} 2 \mu \mathrm{M}$ reverse primer (Universal Adaptor PCR Primer), $10 \mu \mathrm{l} 2 \times$ All-in-One $^{\mathrm{TM}}$ miRNA Q-PCR buffer and $5.5 \mu$ l nuclease-free water. The reactions were incubated at $95^{\circ} \mathrm{C}$ for $10 \mathrm{~min}$, then were cycled 36 times through $95^{\circ} \mathrm{C} / 10 \mathrm{~s}, 55^{\circ} \mathrm{C} / 20 \mathrm{~s}$ and $72^{\circ} \mathrm{C} / 10 \mathrm{~s}$. After the reactions had been completed, the threshold was manually set and the threshold cycle (CT) was automatically recorded. All reactions were replicated twice per biological sample. A $4 \mu$ l aliquot of each reaction product was subjected to $3 \%$ agarose electrophoresis. The relative expression level of the miRNAs was calculated using the $2^{-\Delta \Delta C T}$ method [46], and the data were normalized on the basis of $18 \mathrm{~s}$ rRNA CT values.

\section{Target gene prediction and annotation of novel miRNAs}

Potential targets of novel miRNAs were predicted in silico a software package developed by the Huada Genomic Center (Beijing, China, http://www.rnaiweb. com/RNAi/MicroRNA/MicroRNA_Tools__Software/ MicroRNA_Target_Scan/index.html) mounted in the A. thaliana transcript database ftp://ftp.tigr.org/pub/ data/a_thaliana/ath1/SEQUENCES/. The criteria applied were as described elsewhere [14,38]. The potential targets of conserved miRNA families were identified by a search in the website http://bioinfo3.noble.org/psRNATarget/, with the following settings applied: transcript/genomic library A. thaliana TAIR7 cDNA [25/04/2007 release]; range of maximum expectation 1-5; range of maximum circles 1-3; range of central mismatch for translational inhibition 9-11 nt. A BlastN search against a reference $A$. thaliana database including UniProt entries http://www. uniprot.org/ was used to provide gene ontologies, expressed as three independent hierarchies: biological process, cell component and molecular function.

\section{Additional material}

Additional file 1: Table S1 - Conserved miRNAs from $R$. glutinosa The abbreviations represent: ath, $A$. thaliana; gma, soybean; ptc, black poplar; vvi, grape; osa, rice. The plus symbols indicate: ++ , miRNA sequences of $R$. glutinosa were exactly identical to those in other species; + , miRNA sequences of $R$. glutinosa were conserved in other species but have variations in some nucleotide positions. Table S2 - Candidates of novel miRNAs from R. glutinosa. Table S3 - Predicted targets of novel validated $R$. glutinosa miRNAs. Table S4 - Forward primer sequences of candicate miRNAs using RT-PCR in $R$. glutinosa.

Additional file 2: Secondary structures of candidate miRNAs. Additional file 3: Potential target genes of 29 conserved miRNAs. Additional file 4: Sequence alignments of partial targets of differential expressed miRNAs. 


\section{Acknowledgements}

This work was supported by grants from the National Natural Science Foundation of China (Nos. 30973875, 30772729 and 81072983).

\section{Authors' contributions}

YY carried out R. glutinosa small RNA isolation, participated in the computational analyses and drafted manuscript. XC participated in the bioinformatics analyses and drafted manuscript. JC carried out the molecular genetic studies. HX participated in the sequence alignment. JL carried out field R. glutinosa plant cultivation and collection. ZZ conceived of the study, participated in its design and drafted and amended the manuscript. All authors read and approved the final manuscript.

\section{Received: 3 November 2010 Accepted: 26 March 2011}

Published: 26 March 2011

\section{References}

1. Wen XS, Yang SL, Wei JH, Zheng JH: Textual research on planting history of Rehmannia glutinosa and its cultivated varieties. Chinese Traditional and Herbal Drugs 2002, 33(10):946-949, (in Chinese).

2. Li XE, Chen SL, Wei SQ, Wei JH, Lan J: Analysis on adaptive area of Rehmannia glutinosa L. and it's class partition. China Journal of Chinese Materia Medica 2006, 31(4):344-346, (in Chinese).

3. Yu FP, Yang L: Preliminary study of Rehmannia mosaic virus. Acta Phytopathologica Sinica 1994, 24:310-310, (in Chinese).

4. Zhao YJ, Chen Z: Effect of N, P and $\mathrm{K}$ supply on dry matter accumulation and nutrient contents of Rehmannia glutinosa Libosch. Jorunal of Chinese Medicinal Materials 1991, 14:3-6, (in Chinese).

5. Du JF, Yin WJ, Zhang ZY, Hou J, Huang J, Li J: Autotoxicity and phenolic acids content in soils with different planting interval years of Rehmannia glutinosa. Chinese Journal of Ecology 2009, 28(3):445-450, (in Chinese).

6. Wu ZW, Wang MD, Liu XY, Chen HG, Jia XC: Phenolic compounds accumulation in continuously cropped Rehmannia glutinosa soil and their effects on R. glutinosa growth. Chinese Journal of Ecology 2009, 28(4):660-664, (in Chinese).

7. Yin WJ, Du JF, Li J, Zhang ZY: Effects of continuous cropping obstacle on growth of Rehmannia glutinosa. China Journal of Chinese Materia Medica 2009, 34(1):18-21, (in Chinese).

8. Bartel DP: MicroRNAs: genomics, biogenesis, mechanism, and function. Cell 2004, 116:281-297.

9. Reinhart BJ, Weinstein EG, Rhoades MW, Bartel B, Bartel DP: MicroRNAs in plants. Genes \& Development 2002, 16(13):1616-1626

10. Sunkar R, Girke T, Zhu JK: Identification and characterization of endogenous small interfering RNAs from rice. Nucleic Acids Research 2005, 33(14):4443-4454.

11. Lu S, Sun YH, Shi R, Clark C, Li L, Chiang VL: Novel and mechanical stressresponsive MicroRNAs in Populus trichocarpa that are absent from Arabidopsis. Plant Cell 2005, 17:2186-2203.

12. Dezulian T, Palatnik J, Huson D, Weigel D: Conservation and divergence of microRNA families in plants. Genome Biology 2005, 6:p13.

13. Wang XJ, Reyes $J$, Chua NH, Gaasterland T: Prediction and identification of Arabidopsis thaliana microRNAs and their mRNA targets. Genome Biology 2004, 5:R65.

14. Jones-Rhoades MW, Bartel DP: Computational identification of plant microRNAs and their targets, including a stress-induced miRNA. Molecular Cell 2004, 14(6):787-799.

15. Adai A, Johnson C, Mlotshwa S, Archer-Evans S, Manocha V, Vance V, Sundaresan V: Computational prediction of miRNAs in Arabidopsis thaliana. Genome Research 2005, 15:78-91

16. Rhoades MW, Reinhart BJ, Lim LP, Burge CB, Bartel B, Bartel DP: Prediction of plant microRNA targets. Cell 2002, 110:513-520.

17. He L, Hannon GJ: Small RNAs with a big role in gene regulation. Nature Reviews Genetics 2004, 5:522-531.

18. Navarro L, Dunoyer P, Jay F, Arnold B, Dharmasiri N, Estel le M, Voinnet $\mathrm{O}$, Jones JD: A plant miRNA contributes to antibacterial resistance by repressing auxin signaling. Science 2006, 312:436-439.

19. Glazov EA, Cottee PA, Barris WC, Moore RJ, Dalrymple BP, Tizard ML: A microRNA catalog of the developing chicken embryo identified by a deep sequencing approach. Genome Research 2008, 18:957-964.
20. Chen X, Gao C, Li H, Huang L, Sun Q, Dong Y, Tian C, Gao S, Dong H, Guan D, Hu X, Zhao S, Li L, Zhu L, Yan Q, Zhang J, Zen K, Zhang CY: Identification and characterisation of microRNAs in raw milk during different periods of lactation, commercial fluid, and powdered milk products. Cell Research 2010.

21. Liang C, Zhang X, Zou J, Xu D, Su F, Ye N: Identification of miRNA from Porphyra yezoensis by high-throughput sequencing and bioinformatics analysis. PLoS One 2010, 5:e10698.

22. Kwak PB, Wang QQ, Chen XS, Qiu CX, Yang ZM: Enrichment of a set of microRNAs during the cotton fiber development. BMC Genomics 2009, 10:457-467.

23. Xu Q, Liu Y, Zhu A, Wu X, Ye J, Yu K, Guo W, Deng X: Discovery and comparative profiling of microRNAs in a sweet orange red-flesh mutant and its wild type. BMC Genomics 2010, 11:246-252

24. Ruan MB, Zhao YT, Meng ZH, Wang XJ, Yang WC: Conserved miRNA analysis in Gossypium hirsutum through small RNA sequencing. Genomics 2009, 94(4):263-268.

25. Liu S, Li D, Li Q, Zhao P, Xiang Z, Xia Q: MicroRNAs of Bombyx mori identified by Solexa sequencing. BMC Genomics 2010, 11:148-160.

26. Szittya G, Moxon S, Santos DM, Jing R, Fevereiro MP, Moulton V, Dalmay T: High-throughput sequencing of Medicago truncatula short RNAs identifies eight new miRNA families. BMC Genomics 2008, 9:593-601.

27. Zhao CZ, Xia H, Frazier TP, Yao YY, Bi YP, Li AQ, Li MJ, Li CS, Zhang BH, Wang XJ: Deep sequencing identifies novel and conserved microRNAs in peanuts (Arachis hypogaea L.). BMC Plant Biology 2010, 10:3-14.

28. Yao Y, Guo G, Ni Z, Sunkar R, Du J, Zhu JK, Sun Q: Cloning and characterization of microRNAs from wheat (Triticum aestivum L.). Genome Biology 2007, 8:R96.

29. Sunkar R, Girke T, Zhu JK: Identification and characterization of endogenous small interfering RNAs from rice. Nucleic Acids Research 2005, 33(14):4443-4454.

30. Taylor PF, Xie F, Freistaedter A, Burklew CE, Zhang B: Identification and characterization of microRNAs and their target genes in tobacco (Nicotiana tabacum). Planta 2010

31. Lang Q, Jin C, Lai L, Feng J, Chen S, Chen J: Tobacco microRNAs prediction and their expression infected with Cucumber mosaic virus and Potato virus X. Molecular Biology Reports 2010.

32. Zhang $X$, Li H, Zhang J, Zhang C, Gong P, Ziaf K, Xiao F, Ye Z: Expression of artificial microRNAs in tomato confers efficient and stable virus resistance in a cell-autonomous manner. Transgenic Research 2010.

33. Sunkar R, Zhu JK: Novel and stress-regulated microRNAs and other small RNAs from Arabidopsis. Plant Cell 2004, 16:2001-2019.

34. Mi S, Cai T, Hu Y, Chen Y, Hodges E, Ni F, Wu L, Li S, Zhou H, Long C, Chen S, Hannon GJ, Qi Y: Sorting of small RNAs into Arabidopsis argonaute complexes is directed by the $5^{\prime}$ terminal nucleotide. Cell 2008, 133(1):116-127.

35. Meyers BC, Axtell MJ, Bartel B, Bartel DP, Baulcombe D, Bowman JL, Cao X Carrington JC, Chen X, Green PJ, Griffiths-Jones S, Jacobsen SE, Mallory AC, Martienssen RA, Poethig RS, Qi Y, Vaucheret H, Voinnet O, Watanabe Y, Weigel D, Zhu JK: Criteria for annotation of plant microRNAs. Plant Cell 2008, 20:3186-3790.

36. Jones-Rhoades MW, Bartel DP, Bartel B: MicroRNAs and their regulatory roles in plants. Annual Review of Plant Biology 2006, 57:19-53

37. Audic S, Claverie JM: The Significance of Digital Gene Expression Profiles. Genome Research 1997, 7:986-995.

38. Bonnet E, Wuyts J, Rouze P, Van de PY: Detection of 91 potential conserved plant microRNAs in Arabidopsis thaliana and Oryza sativa identifies important target genes. Proceedings of the National Academy of Sciences of the United States of America 2004, 101(31):11511-11516.

39. Xie K, Wu C, Xiong L: Genomic organization, differential expression and interaction of SQUAMOSA promoter-binding-like transcription factors and microRNA156 in rice. Plant Physiol 2006, 142(1):280-293.

40. Wu G, Poething RS: Temporal regulation of shoot development in Arabidopsis thaliana by miR156 and its target SPL3. Development 2006, 133(18):3539-3547.

41. Wang JW, Czech B, Weigel D: MiR156-regulated SPL transcription factors define an endogenous flowering pathway in Arabidopsis thaliana. Cell 2009, 138(4):738-749.

42. Gutierrez L, Bussell JD, Pacurar DI, Schwambach J, Pacurar M, Bellini C: Phenotypic plasticity of adventitious rooting in Arabidopsis is controlled 
by complex regulation of AUXIN RESPONSE FACTOR transcripts and microRNA abundance. Plant Cell 2009, 21(10):3119-3132.

43. Barrero JM, Gonzalez-Bayon R, del Pozo JC, Ponce MR, Micol JL: INCURVATA2 encodes the catalytic subunit of DNA polymerase alpha and interacts with genes involved in chromatin-mediated cellular memory in Arabidopsis thaliana. Plant Cell 2007, 19(9):2822-2838.

44. Li R, Li Y, Kristiansen K, Wang J: SOAP: short oligonucleotide alignment program. Bioinformatics 2008, 24(5):713-714.

45. Lu C, Kulkarni K, Souret FF, Valliappan RM, Tej SS, Poethig RS, Henderson Rl, Jacobsen SE, Wang W, Green PJ, Meyers BC: RNA-dependent RNA polymerase-2 mutant microRNAs and other small RNAs enriched in the Arabidopsis. Genome Research 2006, 16:1276-1288.

46. Livak KJ, Schmittgen TD: Analysis of relative gene expression data using real-time quantitative PCR and the 2 (-Delta Delta C (T)). Method 25(4):402-408.

doi:10.1186/1471-2229-11-53

Cite this article as: Yang et al:: Differential miRNA expression in

Rehmannia glutinosa plants subjected to continuous cropping. BMC

Plant Biology 2011 11:53.

\section{Submit your next manuscript to BioMed Central} and take full advantage of:

- Convenient online submission

- Thorough peer review

- No space constraints or color figure charges

- Immediate publication on acceptance

- Inclusion in PubMed, CAS, Scopus and Google Scholar

- Research which is freely available for redistribution

Submit your manuscript at www.biomedcentral.com/submit 